\title{
Instrument for evaluation of sedentary lifestyle in patients with high blood pressure
}

\author{
Instrumento para avaliação de estilo de vida sedentário em pacientes com hipertensão \\ Instrumento para evaluación de estilo de vida sedentario en pacientes con hipertensión
}

\section{Marcos Venícios de Oliveira Lopes', Viviane Martins da Silva', Thelma Leite de Araujo', Nirla Gomes Guedes', Larissa Castelo Guedes Martins", lane Ximenes Teixeira"}

'Universidade Federal do Ceará, School of Pharmacy Dentistry and Nursing, Department of Nursing. Fortaleza-CE, Brazil. "Universidade Federal do Ceará, School of Pharmacy Dentistry and Nursing, Graduate Program in Nursing. Fortaleza-CE, Brazil.

How to cite this article:

Lopes MVO, Silva VM, Araujo TL, Guedes NG, Martins LCG, Teixeira IX. Instrument for evaluation of sedentary lifestyle in patients with high blood pressure. Rev Bras Enferm. 2015;68(3):386-92.

DOI: http://dx.doi.org/10.1590/0034-7167.2015680310i

Submited: 12-13-2014 Aproved: 03-19-2015

\begin{abstract}
Objective: this article describes the diagnostic accuracy of the International Physical Activity Questionnaire to identify the nursing diagnosis of sedentary lifestyle. Method: a diagnostic accuracy study was developed with 240 individuals with established high blood pressure. The analysis of diagnostic accuracy was based on measures of sensitivity, specificity, predictive values, likelihood ratios, efficiency, diagnostic odds ratio, Youden index, and area under the receiver-operating characteristic curve. Results: statistical differences between genders were observed for activities of moderate intensity and for total physical activity. Age was negatively correlated with activities of moderate intensity and total physical activity. Conclusion: the analysis of area under the receiver-operating characteristic curve for moderate intensity activities, walking, and total physical activity showed that the International Physical Activity Questionnaire present moderate capacity to correctly classify individuals with and without sedentary lifestyle.
\end{abstract}

Key words: Nursing Diagnosis; Arterial Pressure; Life Style; Motor Activity.

\section{RESUMO}

Objetivo: este artigo descreve a acurácia diagnóstica do International Physical Activity Questionnaire para a identificação do diagnóstico de enfermagem Estilo de vida sedentário. Método: o estudo foi desenvolvido com 240 indivíduos com hipertensão arterial estabelecida. A análise da acurácia diagnóstica foi baseada em medidas de sensibilidade, especificidade, valores preditivos, razões de verossimilhança, eficiência, odds ratio diagnóstica, índice de Youden, e área sob a curva característica operador-receptor. Resultados: diferenças estatísticas entre os sexos foram observadas para as atividades de intensidade moderada e para a atividade física total. Idade foi negativamente correlacionada com atividades de intensidade moderada e atividade física total. Conclusão: a análise da área sob a curva característica operador-receptor para as atividades de intensidade moderada, caminhadas, e para atividade física total mostrou que o International Physical Activity Questionnaire apresenta capacidade moderada para classificar corretamente os indivíduos com e sem estilo de vida sedentário.

Descritores: Diagnóstico de Enfermagem; Pressão Arterial; Estilo de Vida; Atividade Motora.

\section{RESUMEN}

Objetivo: este artículo describe la precisión diagnóstica del International Physical Activity Questionnaire en la identificación del diagnóstico enfermero Estilo de vida sedentario. Método: un estudio de precisión diagnóstica se desarrolló con 240 individuos con hipertensión arterial establecida. El análisis de precisión diagnóstica se basó en medidas de sensibilidad, especificidad, valores predictivos, razones de verosimilitud, eficiencia, odds ratio diagnóstica, índice de Youden y área bajo 
la curva característica receptor-operador. Resultados: diferencias estadísticas entre los sexos se observaron para las actividades intensidad moderada y la actividad física total. La edad se correlacionó negativamente con la actividad de intensidad moderada y la actividad física total. Conclusión: el análisis del área bajo la curva característica receptor-operador para las actividades de intensidad moderada, de caminar, y la actividad física total mostró que el International Physical Activity Questionnaire presenta moderada capacidad para clasificar correctamente los sujetos con y sin el estilo de vida sedentario.

Palabras clave: Diagnóstico de Enfermería; Presión Arterial; Estilo de Vida; Actividad Motora.

\section{CORRESPONDING AUTHORＭarcos Venícios de Oliveira LopesＥ-mail: marcos@ufc.br}

\section{INTRODUCTION}

Sedentary lifestyle was recognised by NANDA International in 2004 as a nursing diagnosis and was defined in that report as a habit of life that is characterised by a low physical activity level. Its defining characteristics include choosing a daily routine lacking physical exercise, demonstrates physical deconditioning, and verbalising a preference for activities low in physical activity. Related factors are noted to be: deficient knowledge of the health benefits of physical exercise, lack of training for the accomplishment of physical exercise, lack of resources, lack of motivation, and lack of interest ${ }^{(1)}$.

It is important to emphasise that there are global concerns about this lifestyle because it constitutes a health risk capable of having severe consequences for the lives of individuals, families, and communities. An example of a target population for sedentary lifestyle studies is people with high blood pressure. Sedentary lifestyle has been identified as a risk factor for cardiovascular diseases, and heart attacks have been associated with arterial hypertension in people who do not perform any kind of physical activity ${ }^{(2)}$.

Furthermore, there is worldwide interest in the development of a specific language to describe the phenomena of nursing. However, few studies have evaluated instruments for the accurate identification of individuals with and without specific health conditions, especially instruments for use with nursing diagnoses.

The International Physical Activity Questionnaire (IPAQ) is an instrument that has been designed and tested for population surveillance of physical activity among adults. The IPAQ presents characteristics and a structure that facilitate the evaluation of physical activity level in adults. This instrument was not developed specifically for nursing evaluation, but this questionnaire can assist nurses in the identification of patients with low physical activity level and in the discrimination between sedentary and non-sedentary patients.

Adequate assessment of individuals with high blood pressure and sedentary lifestyles is essential for improved quality of care because it directs assistance toward the specific needs of these individuals. Therefore, an accurate identification of individuals with this nursing diagnosis can assist the clinical practice of nurses who care for these patients.

Related to this point, identifying clinical indicators with a good predictive value for a specific nursing diagnosis can contribute to increasing diagnostic accuracy and to improving the reliability of the diagnostic inference process. Accurate diagnostic inferences increase the effectiveness of care by permitting nurses to choose specific actions oriented toward the resolution and control of identified problems. Conversely, interpretations of low accuracy can lead to the neglect of real or potential problems and cause damage to the patient ${ }^{(3)}$.

On the other hand, the evaluation of physical activity level is hindered by the lack of standardised, precise instruments that can be used in population studies and in different social contexts. The defining characteristics of sedentary lifestyle represent measures that include the relationship between habits and physical activity. Thus, the intensity, frequency, type, and time of physical activity play important roles in identifying this nursing diagnosis.

The physical activity deficit is an important characteristic of the broader concept of sedentary lifestyle. Barnett-Damewood and Carlson-Catalano ${ }^{(4)}$ presented an initial proposal for the nursing diagnosis of physical activity deficit, which was defined as a state in which an individual does not wilfully expend any energy that would produce health benefits above what is required to sustain the body's vital functions in the waking state.

Spanish researchers subsequently presented a broader proposal for diagnosis ${ }^{(5)}$. The diagnosis was identified as sedentary lifestyle, and this new proposal included additional defining characteristics and related factors that denote available resources and personal interest in the development of physical activity. Recently, some studies have attempted to validate the clinical indicators of sedentary lifestyle and provide greater insight into its predictive power ${ }^{(6)}$.

Currently, the nursing diagnosis sedentary lifestyle includes the relationship between habits and physical activity. Unfortunately, there is no consensus regarding strategies or techniques to measure physical activity level, although instruments have been developed to attempt to measure physical activity. For example, Harada et al. ${ }^{(7)}$ assessed the knowngroups and construct validity of measures from the CHAMPS Physical Activity Questionnaire, the Physical Activity Survey for the Elderly (PASE), and the Yale Physical Activity Survey (YPAS). The authors reported that these instruments may perform better for certain segments of the older adult population. Weston et al. ${ }^{(8)}$ assessed the reliability and validity of the Previous Day Physical Activity Recall (PDPAR), a self-report instrument designed to measure physical activity in youths. Welk et al. ${ }^{(9)}$ argued that a number of different measurement approaches have been identified to assess children's activity, but no specific method can be identified as the best option for all studies. These instruments have been developed for use in 
specific populations (elderly or children), and no studies exist that evaluate instruments measuring physical activity level as a predictor of a nursing diagnosis of sedentary lifestyle.

The International Physical Activity Questionnaire (IPAQ) is an instrument designed and tested for population surveillance of physical activity among adults (age range of 15-69 years). The short and long versions of this instrument contain data on walking, moderate-intensity activities, and vigorous-intensity activities in different contexts (work environment, house tasks, transportation, and leisure) during the last seven days or a regular week. Both categorical and continuous indicators of physical activity can be reported with the IPAQ ${ }^{(10)}$.

The continuous indicators in IPAQ are computed by weighting each type of activity by its energy requirements defined in METs to yield a score in MET-minutes. METs are multiples of the resting metabolic rate, and a MET-minute is computed by multiplying the MET score of an activity by the minutes performed. MET-minute scores are equivalent to kilocalories for a $60-k i l o g r a m$ person. Kilocalories may be computed from METminutes using the following equation: MET-min $x$ (weight in kilograms/60 kilograms). MET-minutes/day or MET-minutes/ week can be presented, although the latter is more frequently used and is thus recommended. The formulas for computing MET-minutes/week for each type of activity were derived from the IPAQ reliability study undertaken in 2000-2001(10). The categorical variables represent three levels of physical activity proposed to classify populations: low, moderate, and high. They are defined by mean algorithms that include both the total volume and the number of days or sessions of physical activity.

Thus, based on the explained above, the aim of this study was to estimate the accuracy of the IPAQ to correctly classify individuals with or without the nursing diagnosis Sedentary Lifestyle.

\section{METHOD}

\section{Design}

A phase III diagnostic test study was conducted with 240 individuals (ranging in age from 18 to 69 years) with confirmed high blood pressure. The individuals were followed up in the hypertension programme of a reference centre for the treatment of arterial hypertension and diabetes mellitus. Phase III studies allow us to verify if, among the patients who are clinically suspected of presenting the diagnosis, the test (IPAQ) differentiates between those with and without a diagnosis ${ }^{(11)}$.

\section{Sample and participants}

From 240 patients evaluated for total physical activity, 224 presented activities related to walking, 215 performed moderate-intensity activities, and only 14 performed vigorous-intensity activities. Any medical contraindications for physical activity mentioned by the individuals were criteria for exclusion, as were cognitive problems that rendered the data collection of pertinent information impossible.

A cross-sectional design was used, and patients were selected consecutively. The sample size was defined based on the indicated formula for accuracy studies of a single test ${ }^{(12)}$ using the following parameters: a confidence level of $95 \%$, desired width of one-half of the 95\% confidence interval of $9 \%$, and a conjectured sensitivity of the IPAQ equal to $70 \%$.

\section{Instruments}

For this analysis, we used an instrument proposed by the Cooperative Project/World Organization of National Colleges and Academies ${ }^{(13)}$, an instrument proposed by Martins and Petroski ${ }^{(14)}$ that measures the perception of physical activity barriers, and questions proposed by InteliHealth Inc. ${ }^{(15)}$ about physical activities related to health. These instruments were used to identify the defining characteristics and related factors of the nursing diagnosis sedentary lifestyle and to allow the clinical judgment by the readers.

The instrument proposed by the Cooperative Project/World Organization of National Colleges and Academies was used to assess physical fitness. This instrument was considered reliable for measuring the physical condition in a short period of time, since the Spearman correlation coefficient ranged from 0.66 to $0.81^{(13)}$. The instrument proposed by Martins and Petroski ${ }^{(14)}$ was used to identify the barriers to physical activity, which has been validated on the applicability and clarity, and showed acceptable reproducibility with Pearson's correlation test between 0.67 and 0.97 .

Specific knowledge about the importance of physical activity was assessed by the number of correct answers in twelve questions on physical activity related to health, which were proposed by InteliHealth ${ }^{\otimes}$ Inc. ${ }^{(15)}$. The information contained on the website are reviewed and approved by health professionals, InteliHealth publishers and academic partners at Harvard Medical School and Columbia University College of Dental Medicine.

The questionnaire was submitted to a pre-test in order to verify their suitability to the study objectives. The resulting comments were incorporated and included the final form. The 14 individuals who participated in the pre-test were excluded from the final analysis.

\section{Procedures}

Unfortunately, no measures or techniques serve as a gold standard for the identification of nursing diagnoses. Thus, in the present study the gold standard was based on agreement among three independent readers in identifying the presence of a sedentary lifestyle. The readers were nurses responsible for diagnostic inference and were selected based on the following criteria: a master's degree, published articles about nursing diagnosis and a completed master's dissertation on nursing diagnosis.

Data collection was performed by one of the authors in accordance with operational definitions previously constructed for each variable that compose the diagnosis sedentary lifestyle. The application of the instruments was done in a private room at the time patients waited for their medical consultation. These data were sent the raters who independently performed the diagnostic inference. Initially, the agreement between the raters, measured by Cohen's kappa, ranged between 0.58 and 0.79 . So, we decided to organize the data on the diagnostic inference based on majority rule (i.e., when at least two readers agreed on the final decision). This strategy was used to minimise bias from readers' individual opinions. 
The use of majority rule facilitated the attainment of an agreement level between 0.67 and 0.91 based on Cohen's kappa.

Next, the readers' analyses were compared with the IPAQ data, and the comparison was used to establish accuracy measures. Data referring to the continuous variables of IPAQ were recorded in MET-minutes/week. The IPAQ data were collected by one of the authors after the readers' evaluations. The readers were blinded to the IPAQ data.

\section{Data analysis}

Descriptive statistics were used to describe the demographic and clinical characteristics of patients. The data were examined by Gaussian distribution with the Shapiro-Wilk W test. The Mann-Whitney $U$ test was used for difference median analysis, and Spearman's rho was calculated for correlation analysis.

Analysis of the accuracy characteristics of IPAQ was based on measures of sensitivity, specificity, predictive values, likelihood ratios, the diagnostic odds ratio, the Youden index, and the area under the receiver operating characteristic (ROC) curve of IPAQ, with their respective 95\% confidence intervals estimated by the DeLong method.

In this study, sensitivity was defined as the probability of a positive test in patients with a nursing diagnosis. Specificity was the probability of a negative test in patients without a nursing diagnosis. The predictive value of IPAQ, if positive, was the probability of a nursing diagnosis in patients with a positive test; if negative, it represented the probability of an absence of a nursing diagnosis in patients with a negative test ${ }^{(11)}$.

Other definitions were used: the likelihood ratio represent the probability of a positive/negative test in patients with a nursing diagnosis, divided by the probability of this test in patients without a nursing diagnosis. The diagnostic odds ratio represented the ratio between the positive likelihood ratio and the negative likelihood ratio. The Youden index measured the effectiveness of a diagnostic marker and enabled the selection of an optimal threshold value (cut-off point) for the marker. The area under the ROC curve represented the capacity to correctly classify individuals with and without a sedentary lifestyle. This measure ranged from 0.5 to 1 . The capacity to correctly classify individuals is greater when this value is close to 1 . The area under the ROC curve was used as the primary criterion for determining the extent of accuracy. The statistical significance of the likelihood ratios was verified by the $95 \%$ confidence interval (which does not contain the value 1).

\section{Ethical considerations}

Ethical approval was obtained from the internal committee of the institute. The patients provided written, informed consent prior to the collection of data. Confidentiality of medical information and patients' identity was guaranteed.

\section{RESULTS}

\section{Patients' demographic and clinical data}

The majority of individuals were female $(65.5 \%)$, Catholic $(74.5 \%)$, and married $(64.5 \%)$. The median education was nine years and the mean age was 54.6 years (ranging from 18 to 69 years). Individuals with high levels of body fat predominated, with $80 \%$ of the participants were classified as overweight or obese. Additionally, $70 \%$ of the studied individuals had diabetes mellitus, and half of the participants had known about their condition for more than 10 years.

\section{Patients' IPAQ data}

In relation to IPAQ values, all specific types of activity followed non-Gaussian distributions. For specific types of activity, the calculated median of walking was $594 \mathrm{MET}$-minutes (interquartile range $=693 ; \mathrm{W}=0.8112 ; \mathrm{p}<0.001)$, the median of moderate-intensity activity was 1140 (interquartile range $=1469.1 ; \mathrm{W}=0.8689$; $\mathrm{p}=0.003$ ), and the median of total physical activity was 1474 (interquartile range $=1805.8 ; \mathrm{W}=0.8541 ; \mathrm{p}<0.001$ ).

Statistical differences in physical activity level by gender were identified. Women presented higher values for moderateintensity activities ( 1270 vs. 760; $U=3288 ; p=0.004$ ) and for total physical activity (1656 vs. $1017 ; U=6674 ; p=0.001$ ). Furthermore, age presented a negative correlation with activities of moderate intensity (rho $=-0.207 ; \mathrm{p}=0.002$ ) and total physical activity ( $r$ o $=-0.157 ; p=0.009$ ). No correlation was found between physical activity level and body mass index or duration of hypertension.

\section{Accuracy measures of IPAQ by majority rule}

In the identification of the nursing diagnosis of sedentary lifestyle using the IPAQ values, the area under the ROC curve for total physical activity was $0.697(95 \% \mathrm{Cl}$ : 0.640-0.753). The cut-off limits with a 0.95 inconclusive tolerance were large, showing that for values lower than 528 MET-minutes, the sensitivity was equal to $95.16 \%$, whereas for values higher than 4098.2 MET-minutes, the specificity was $94.81 \%$. In both cases, the likelihood ratio was statistically significant (95\% Cl: 1.22-1.57 for inferior limit; 95\% Cl: 1.16-4.67 for superior limit). Other criteria showed sensitivity higher than $80 \%$ and specificity lower than $70 \%$ (Table 1 ). Similar results were found for the data on walking and moderate-intensity activities and are summarized in the Tables 2 and 3 .

\section{DISCUSSION}

The accurate identification of individuals with sedentary lifestyle is an important challenge for health professionals. Individuals who have sedentary lifestyles show increased mortality compared to those who are physically active. The high prevalence of this nursing diagnosis in the studied sample demonstrates the need for programmes to modify health habits.

Risk factor modification and organisation of training programmes with ensured participation of patients and their relatives are of critical importance in improving their quality of life ${ }^{(16)}$. Sin et al. ${ }^{(17)}$ found that some personal factors and health status are significant factors influencing the participant's adherence to physical activity recommendations and quality of life in a cardiac rehabilitation programme. However, there were no significant relationships among personal factors, health status, and physical activity scores from programme completion to 1-year follow-up. 
There is conflicting evidence on the positive effects of physical activity on cardiac risk factors probably influenced by variations in the methods for measurement of physical activity ${ }^{(18)}$. Thus, more research is needed with larger samples, better control of extraneous variables, and the use of physical activity measures which have been submitted to appropriate psychometric tests.

In relation to the spectrum of sedentary lifestyles, the patients enrolled in this study presented similar relationships between physical activity level and gender or age when compared to a previous study ${ }^{(19)}$. However, these authors reported that individuals with higher levels of physical activity had better values for other clinical indicators, particularly body mass index, systolic blood pressure, and dietary fat. This finding can be related to specific characteristics of the evaluated patients. When the study was developed, the patients presented deficiencies in arterial pressure control and were strongly encouraged to adopt lifestyle changes.

The differences identified by gender may have been influenced by sociodemographic factors. Kim et al. ${ }^{(20)}$ reported that sociodemographic factors related to work and family roles were statistically significant for explaining the physical activity levels of women. In this study, the accuracy measures demonstrated that women had a better level of physical activity when compared to men. These differences from other studies may have been caused by the fact that IPAQ assesses domestic activities.

Wong and Wong ${ }^{(21)}$ stated that the results of some studies that included women in their study populations have associated the low level of physical activity with an increased risk of myocardial infarction and stroke in middle-aged women. In this study, the accuracy measurements showed that women had a higher level of physical activity when compared to men. These differences in other studies may have been caused by the fact that IPAQ evaluates domestic activities.

Regarding the type of physical activity, Lin et al. ${ }^{(22)}$ found that leisurely walking was the most frequent leisure-time physical activity for individuals with chronic diseases and that age, gender, living arrangement, affective feeling, and environmental control were significant variables affecting leisure-time physical activity. Another study found a relationship between the amount of physical activity during leisure time and the perceived importance of physical exercise. That study reported that age and education were the variables that were most likely to predict the amount of physical activity ${ }^{(23)}$. In our study, these relationships were observed only for moderateintensity activity and total physical activity.

Lee et al. ${ }^{(24)}$, in a systematic review of 27 randomised controlled trials about the effect of walking intervention on blood pressure control, found a beneficial effect of walking on blood pressure. This effect was observed in studies that tended to employ moderate- to high-intensity walking and a longer intervention period than those trials not showing the beneficial effect. Unfortunately, the small number of patients who performed vigorous-intensity physical activity in our sample prevented an evaluation on IPAQ's accuracy characteristics relating to vigorous activity. Along these lines, Lee et al. ${ }^{(24)}$ argue that future research investigating the effect of walking intensity on blood pressure levels and a rigorous design of walking interventions to achieve better adherence and methodological quality are required. Thus, an evaluation of the accuracy characteristics of health assessment instruments is important for adequate clinical reasoning.

Diagnostic test studies present many limitations in terms of possible biases. In the present study, two biases may be considered: the imperfect gold standard bias and the spectrum bias. The imperfect gold standard bias is related to the evaluation of the presence or absence of a nursing diagnosis based on the evaluation by three readers. We attempted to minimise this effect by using the majority rule. The spectrum bias is related to the exclusion of patients with several clinical conditions ${ }^{(12)}$. Our patients had a strong indication to change their lifestyle due to the difficulty of controlling their blood pressure. Furthermore, the low per capita income in our sample may have influenced the observed values. Importantly, a lack of resources is a related factor mentioned by NANDA International for the sedentary lifestyle.

Table 1 - Accuracy characteristics of IPAQ for identification of sedentary lifestyle (SL) according to total physical activity among patients with high blood pressure, based on comparison with majority rule

\begin{tabular}{lcccc}
\hline Best cut-off estimations with 0,95 confidence limits & IPAQ Values & Sensitivity $(95 \%$ Cl) & Specificity $(95 \%$ Cl $)$ & PLR (95\% Cl) \\
\hline Max. efficiency & 924.0 & $84.68(77.31-89.97)$ & $49.35(41.57-57.17)$ & $1.67(1.39-2.01)$ \\
Max. Diagnostic Odds Ratio & 346.5 & $98.39(94.31-99.56)$ & $19.48(14.00-26.45)$ & $1.22(1.11-1.34)$ \\
Max. accuracy area & 924.0 & $84.68(77.31-89.97)$ & $49.35(41.57-57.17)$ & $1.67(1.39-2.01)$ \\
Max. Sensitivity + Specificity & 792.0 & $88.71(81.94-93.15)$ & $45.45(37.80-53.33)$ & $1.63(1.38-1.93)$ \\
Max. Youden & 792.0 & $88.71(81.94-93.15)$ & $45.45(37.80-53.33)$ & $1.63(1.38-1.93)$ \\
Sensitivity = Specificity & 1513.5 & $62.10(53.32-70.15)$ & $62.34(54.47-69.60)$ & $1.65(1.29-2.11)$ \\
Min. ROC distance & 1656.0 & $58.87(50.07-67.14)$ & $68.18(60.46-75.02)$ & $1.85(1.41-2.42)$ \\
\hline Non-parametric inconclusive cut-off limits with 0.95 inconclusive tolerance & & & \\
\hline & IPAQ Values & Sensitivity (95\% IT) & Specificity (95\% IT) & PLR (95\% IT) \\
Lower inconclusive & 528.0 & $95.16(89.84-97.76)$ & $31.17(24.39-38.87)$ & $1.38(1.22-1.57)$ \\
Upper inconclusive & 4098.2 & $12.10(7.47-19.00)$ & $94.81(90.08-97.34)$ & $2.33(1.16-4.67)$ \\
\hline
\end{tabular}

Sample prevalence: 44.6; Area under ROC curve: 0.697 [0.640 - 0.753]; PLR - Positive Likelihood Ratio 
Table 2 - Accuracy characteristics of IPAQ for identification of sedentary lifestyle (SL) according to walking activity among patients with high blood pressure, based on comparison with majority rule

\begin{tabular}{lcccc}
\hline Best cut-off estimations with 0,95 confidence limits & IPAQ Values & Sensitivity $(95 \%$ Cl) & Specificity $(95 \%$ Cl $)$ & PLR (95\% Cl) \\
\hline Max. efficiency & 495.0 & $82.61(74.66-88.45)$ & $62.39(53.02-70.91)$ & $2.20(1.70-2.85)$ \\
Max. Diagnostic Odds Ratio & 132.0 & $99.13(95.24-99.85)$ & $14.68(9.24-22.52)$ & $1.16(1.06-1.27)$ \\
Max. accuracy area & 686.4 & $65.22(56.15-73.30)$ & $79.82(71.33-86.28)$ & $3.23(2.18-4.78)$ \\
Max. Sensitivity + Specificity & 686.4 & $65.22(56.15-73.30)$ & $79.82(71.33-86.28)$ & $3.23(2.18-4.78)$ \\
Max. Youden & 686.4 & $65.22(56.15-73.30)$ & $79.82(71.33-86.28)$ & $3.23(2.18-4.78)$ \\
Sensitivity = Specificity & 600.6 & $67.83(58.83-75.67)$ & $73.39(64.41-80.79)$ & $2.55(1.83-3.56)$ \\
Min. ROC distance & 686.4 & $65.22(56.15-73.30)$ & $79.82(71.33-86.28)$ & $3.23(2.18-4.78)$ \\
\hline Non-parametric inconclusive cut-off limits with 0.95 inconclusive tolerance & & & \\
\hline & IPAQ Values & Sensitivity (95\% Cl) & Specificity (95\% Cl) & PLR (95\% Cl) \\
Lower inconclusive & 297 & $94.78(89.08-97.59)$ & $41.28(32.49-50.67)$ & $1.61(1.36-1.91)$ \\
Upper inconclusive & 1980 & $11.30(6.73-18.38)$ & $95.41(89.71-98.02)$ & $2.46(1.03-5.89)$ \\
\hline
\end{tabular}

Sample prevalence: 51.34; Area under ROC curve: 0.769 [0.722 - 0.817]; PLR - Positive Likelihood Ratio

Table 3 - Accuracy characteristics of IPAQ for identification of sedentary lifestyle (SL) according to moderate-intensity activity among patients with high blood pressure, based on comparison with majority rule

\begin{tabular}{|c|c|c|c|c|}
\hline Best cut-off estimations with 0,95 confidence limits & IPAQ Values & Sensitivity $(95 \% \mathrm{Cl})$ & Specificity $(95 \% \mathrm{Cl})$ & $\operatorname{PLR}(95 \% \mathrm{Cl})$ \\
\hline Max. efficiency & 1859.1 & $39.39(30.34-49.24)$ & $81.03(72.95-87.13)$ & $2.08(1.38-3.14)$ \\
\hline Max. Diagnostic Odds Ratio & 449.4 & $91.92(84.86-95.85)$ & $31.03(23.34-39.95)$ & $1.33(1.14-1.56)$ \\
\hline Max. accuracy area & 697.5 & $79.80(70.85-86.52)$ & $42.24(33.64-51.34)$ & $1.38(1.12-1.70)$ \\
\hline Max. Sensitivity + Specificity & 449.4 & $91.92(84.86-95.85)$ & $31.03(23.34-39.95)$ & $1.33(1.14-1.56)$ \\
\hline Max. Youden & 449.4 & $91.92(84.86-95.85)$ & $31.03(23.34-39.95)$ & $1.33(1.14-1.56)$ \\
\hline Sensitivity $=$ Specificity & 1152.0 & $55.56(45.74-64.95)$ & $56.03(46.95-64.73)$ & $1.26(0.96-1.65)$ \\
\hline Min. ROC distance & 1499.7 & $49.49(39.85-59.18)$ & $68.10(59.16-75.89)$ & $1.55(1.13-2.12)$ \\
\hline \multicolumn{5}{|c|}{ Non-parametric inconclusive cut-off limits with 0.95 inconclusive tolerance } \\
\hline & IPAQ Values & Sensitivity $(95 \% \mathrm{Cl})$ & Specificity $(95 \% \mathrm{Cl})$ & $\operatorname{PLR}(95 \% \mathrm{Cl})$ \\
\hline Lower inconclusive & 268.8 & $94.95(88.72-97.82)$ & $15.52(10.05-23.20)$ & $1.12(0.98-1.28)$ \\
\hline Upper inconclusive & 3860.0 & $6.06(2.81-12.60)$ & $94.83(89.17-97.61)$ & $1.17(0.52-2.61)$ \\
\hline
\end{tabular}

Sample prevalence: 46.05; Area under ROC curve: 0.622 [0.554 - 0.690]; PLR - Positive Likelihood Ratio

\section{CONCLUSIONS}

Clinicians can use the IPAQ to identify individuals with a physical activity deficit. Values of total physical activity less than 525 MET-minutes correctly identify $95 \%$ of individuals with low physical activity. These individuals should be evaluated for the presence of other defining characteristics for the diagnosis of sedentary lifestyle. This finding is confirmed by the values of the area under the ROC curve, which suggest the need for additional information to correctly classify individuals with and without the diagnosis.

New diagnostic tools can help to validate specific phenomena in nursing practice. Use of the IPAQ can help nurses to objectively identify individuals with a low level of physical activity and, possibly, with a sedentary lifestyle. Therefore, the correct use of IPAQ can reduce the costs associated with the implementation of unnecessary health programs. Furthermore, an accurate diagnosis reduces the likelihood that individuals with sedentary lifestyles will be deprived of proper guidance to reverse their health situation.

\section{REFERENCES}

1. Herdman TH. NANDA International Nursing diagnoses: Definitions \& classification 2009-2011. Oxford: Wiley-Blackwell; 2009.

2. Hwang WJ, Hong O. Work-related cardiovascular disease risk factors using a socioecological approach: implications for practice and research. Eur J Cardiovasc Nurs [Internet]. 2012 [cited 2013 Apr 05];11(1):114-26. Available from: http://cnu.sagepub.com/content/11/1/114.long 
3. Lunney M. Critical thinking \& nursing diagnoses: case studies \& analyses. Philadelphia: Wiley-Blackwell; 2001.

4. Barnett-Damewood M, Carlson-Catalano J. Physical activity deficit: a proposed nursing diagnosis. Nurs Diagn [Internet]. 2000 Jan-Mar [cited 2013 Apr 05];11(1):24-31. Available from: http://www.ncbi.nlm.nih.gov/pubmed/10847056

5. Guirao-Goris JA, Moreno Pina P, Martínez-Del Campo P. [The validation of the diagnostic content of the diagnostic label “Nursing sedentarism”]. Enferm Clín [Internet]. 2000 [cited 2013 Apr 05];11(4):135-40. Available from: http://www. sciencedirect.com/science/article/pii/S1130862101737060 Spanish.

6. Guedes NG, Lopes MVO, Araujo TL, Moreira RP, Martins LC. Predictive factors of the nursing diagnosis sedentary lifestyle in people with high blood pressure. Public Health Nurs [Internet]. 2011 Mar-Apr [cited 2013 Apr 05];28(2):193-200. Available from: http://onlinelibrary. wiley.com/doi/10.1111/j.1525-1446.2010.00902.x/epdf

7. Harada ND, Chiu V, King AC, Stewart AL. An evaluation of three self-report physical activity instruments for older adults. Med Sci Sports Exerc [Internet]. 2001 [cited 2013 Apr 05];33(6):962-70. Available from: http://www.ncbi. nlm.nih.gov/pubmed/11404662

8. Weston AT, Petosa R, Pate RR. Validation of an instrument for measurement of physical activity in youth. Med Sci Sports Exerc [Internet]. 1997 Jan [cited 2013 Apr 05];29(1):138-43. Available from: http://www.ncbi.nlm. nih.gov/pubmed/9000167

9. Welk GJ, Corbin CB, Dale D. Measurement issues in the assessment of physical activity in children. Res Q Exerc Sport [Internet]. 2000 [cited 2013 Apr 05];71(2 Suppl):S59-S73. Available from: http://www.ncbi.nlm. nih.gov/pubmed/10925827

10. Craig CL, Marshall A, Sjostrom M, Booth ML, Ainsworth BE, Pratt $M$, et al. International physical activity questionnaire: 12 country reliability and validity. Med Sci Sports Exerc [Internet]. 2003 [cited 2013 Apr 05];35(8):1381-95. Available from: http://www.ncbi.nlm.nih.gov/pubmed/12900694

11. Lopes MVO, Silva VM, Araujo TL. Methods for establishing the accuracy of clinical indicators in predicting nursing diagnoses. Int J Nurs Knowl [Internet]. 2012 [cited 2013 Apr 05];23(3):134-9. Available from: http://onlinelibrary. wiley.com/doi/10.1111/j.2047-3095.2012.01213.x/pdf

12. Zhou X, Obuchowski NA, McClish DK. Statistical methods in diagnostic medicine. 2nd ed. New York: Wiley Interscience; 2011.

13. Tudela LL, Ferrer AR. [Cross-cultural adaptation of a health-related quality of life measurement: the Spanish version of the COOP/WONCA cartoons]. Aten Primaria [internet]. 2002 [cited 2013 Apr 05];24(2):75-82. Available from: http:// dps.ua.es/es/documentos/pdf/1999/adaptacion-transcul tural-de-una-medida-de-la-calidad-de-vida.pdf Spanish.

14. Martins MO, Petroski EL. [Measurement of perceived barriers to physical activities: proposed research instrument]. Rev Bras Cineantropom Desempenho Hum [Internet]. 2000 [cited 2013 Apr 05];2(1):58-65. Available from: https://periodi cos.ufsc.br/index.php/rbcdh/article/download/3958/3360 Portuguese.

15. Intelihealth.com/home [Internet]. [place unknown]: Intelihealth; [updated 2015 Mar 30; cited 2013 Apr 05]. Available from: http://www.intelihealth.com/IH/ihtlH/WSIHW0O 0/7165/24439/335060.html?d = dmtContent

16. Sevinc $S, A k y o l$ AD. Cardiac risk factors and quality of life in patients with coronary artery disease. J Clin Nurs [Internet]. 2010 May [cited 2013 Apr 05];19(9-10):1315-25. Available from: http://onlinelibrary.wiley.com/doi/10.111 1/j.1365-2702.2010.03220.x/epdf

17. Sin MK, Sanderson B, Weaver M, Giger J, Pemberton J, Klapow J. Personal characteristics, health status, physical activity, and quality of life in cardiac rehabilitation participants. Int J Nurs Stud [Internet]. 2004 Feb [cited 2013 Apr 05];41(2):173-81. Available from: http://www.sciencedirect. com/science/article/pii/S0020748903001275

18. Houde SC, Melillo KD. Cardiovascular health and physical activity in older adults: an integrative review of research methodology and results. J Adv Nurs [Internet]. 2002 [cited 2013 Apr 05];38(3):219-34. Available from: http://onlinelibra ry.wiley.com/doi/10.1046/j.1365-2648.2002.02172.x/epdf

19. Aldana SG, Whitmer WR, Greenlaw R, Avins AL, Salberg A, Barnhurst $M$, et al. Cardiovascular risk reductions associated with aggressive lifestyle modification and cardiac rehabilitation. Heart Lung [Internet]. 2003 [cited 2013 Apr 05];32(6):374-82. Available from: http://www.sciencedirect. com/science/article/pii/S0147956303001067

20. Kim HK, Kim MJ, Park CG, Kim HO. Do the determinants of physical activity change by physical activity level? J Adv Nurs [Internet]. 2009 Apr [cited 2013 Apr 05];65(4):83643. Available from: http://onlinelibrary.wiley.com/doi/10.11 11/j.1365-2648.2008.04941.x/epdf

21. Wong S, Wong J. Is physical activity as effective in reducing risk of cardiovascular disease as estrogen replacement therapy in postmenopausal women? Int J Nurs Stud [Internet]. 1999 Oct [cited 2013 Apr 05];36(5):405-14. Available from: http://www.sciencedirect.com/science/article/pii/S00207 48999000309

22. Lin YC, Huang LH, Yeh MC, Tai JJ. Leisure-time physical activities for community older people with chronic diseases. J Clin Nurs [Internet]. 2010 Apr [cited 2013 Apr 05];20(7-8):940-9. Available from: http://onlinelibrary. wiley.com/doi/10.1111/j.1365-2702.2009.02877.x/epdf

23. Laffreya SC, Isenberg M. The relationship of internal locus of control, value placed on health, perceived importance of exercise, and participation in physical activity during leisure. Int J Nurs Stud [Internet]. 2003 [cited 2013 Apr 05];40(5):453-9. Available from: http://www.ncbi.nlm.nih. gov/pubmed/6558015

24. Lee LL, Watson MC, Mulvaney CA, Tsai CC, Lo SF. The effect of walking intervention on blood pressure control: a systematic review. Int J Nurs Stud [Internet]. 2010 Dec [cited 2013 Apr 05];47(12):1545-61. Available from: http://www. sciencedirect.com/science/article/pii/S0020748910002981 